\title{
TEMPOS, IDÉIAS E LUGARES \\ O Ensino do Planejamento \\ URBANO E REGIONAL NO BRASIL
}

\author{
Rosélia Périssé da Silva Piquet \\ Ana Clara Torres Ribeiro
}

R E S U M O O artigo resgata, de forma sintética, mudanças observadas no perfil dos cursos de pós-graduação em planejamento urbano e regional no Brasil frente a transformações na economia e no sistema nacional de planejamento. O tema é tratado segundo uma periodização que destaca idéias-mestras de quatro fases do debate nacional sobre planejamento, incluindo seus vínculos com leituras do território: década de 1950 e início da década de 1960 (planejamento para a mudança e relevância da questão do desenvolvimento); década de 1970 e inicio da década de 1980 (planejamento tecnocrático e controle da escala nacional); décadas de 1980 e 1990 (predominio da gestão e centralidade atribuida às forças do mercado); tendências atuais (retorno à questão do desenvolvimento e crescente preocupação com o planejamento de longo prazo).

P A L A V R A S - C H A V E Pós-graduação; planejamento; desenvolvimento; sistema urbano; regiāo.

\section{INTRODUÇÃO}

Desenvolvimento, tema banido da agenda econômica nacional nos últimos 25 anos, retorna ao centro das atenções e, com ele, o papel do planejamento e da formação de pessoal qualificado. Voltam à cena as análises sobre os motivos que induziram o nosso desenvolvimento a apresentar um caráter espacial e socialmente tão desigual. Retomam-se, enfim, as questões de longo prazo, buscando as razóes que, nas palavras de Celso Furtado, levaram à construção interrompida do país.

A constatação desse fato motivou a elaboração do presente texto, que tem como escopo mais amplo o resgate, ainda que sintético, de mudanças observadas no perfil dos cursos de planejamento urbano e regional no Brasil frente às transformaçôes ocorridas no plano econômico e no sistema de planejamento nacional. O tema é tratado segundo uma periodização que seleciona quatro fases históricas distintas, sendo que, em cada uma, são destacadas as idéias-mestras imperantes no período, segundo suas vinculações teórico-ideológicas.

A primeira fase é construída pelas principais concepções de desenvolvimento e subdesenvolvimento dos anos 1950 e 1960 que, no cenário latino-americano, corresponde à fase do "planejamento para a mudança", quando são lançados os primeiros cursos sobre planejamento na América Latina.

A seguir, analisa-se a fase marcada pela conquista do poder por grupos antagônicos aos princípios democráticos, e se aprofunda o caráter centralizador, autoritário e tecnocrático das estruturas de planejamento então existentes. Nesse período, o ensino de planejamento urbano e regional institucionaliza-se em nossas universidades, com a implantação de cursos de pós-graduação stricto sensu. 
$\mathrm{Na}$ terceira fase, indica-se como a crença exacerbada no jogo das forças de mercado leva à rejeição do planejamento, e os cursos da área perdem sua marca de cursos de planejamento e deslocam seus currículos para o campo dos estudos urbanos e regionais. Nessa fase, enquanto a questão regional perde centralidade, os temas urbanos/locais ganham proeminência.

Finalizando o texto, são indicadas as condições da atual retomada das políticas econômicas de longo prazo e o perfil dos cursos da área, que adquirem novas dimensões em número, localização e conteúdo. Nos mais recentes cursos propostos à Capes, não só novos temas são incorporados aos currículos, como também a questão regional é revisitada.

\section{PLANEJANDO O DESENVOLVIMENTO}

No longo período de crescimento econômico e de modernização das estruturas sociais que as sociedades capitalistas ocidentais atravessaram após a Segunda Guerra Mundial, ganham relevo teorias sobre desenvolvimento, em que as políticas públicas compensatórias de base keynesiana são vistas como capazes de fazer frente às fases recessivas dos ciclos econômicos e, de forma complementar, de reduzir desequilíbrios sociais e setoriais derivados da estrita lógica do mercado. O Estado é percebido como o agente político e econômico apto a conduzir projetos de desenvolvimento que resultariam não apenas na expansão do produto e do emprego, mas também, na superação das desigualdades espaciais.

É nesse contexto que o planejamento, até então considerado inerente e exclusivo do sistema socialista, passa a ser aceito e adotado pelos países capitalistas, porquanto é visto como uma técnica de aplicação de políticas. Boa parte dos economistas mais importantes da época, como Jan Timberger, Gunnar Myrdal, François Perroux e Vittório Marrama, acreditava no planejamento, sendo as suas concepçóes amplamente aceitas nos meios especializados latino-americanos.

$\mathrm{Na}$ América Latina, não só havia um paradigma aceito por atores políticos e sociais de grande relevância, como também o desenvolvimento econômico era um objetivo compartilhado. Acreditava-se, firmemente, ser o Estado o principal responsável pelo desenvolvimento. Um Estado investidor, regulador e, ainda, protetor do mercado interno e da indústria nacional.

O pensamento da Comissão Econômica para a América Latina (Cepal) dominava as análises sobre os processos de crescimento das economias latino-americanas e orientava muitas das propostas de política econômica nesse período. Albert Hirschman, Raul Prebisch e Celso Furtado eram seus principais representantes. O debate da época voltavase para as idéias de crescimento, desenvolvimento, subdesenvolvimento e centrava-se em questôes relativas à possibilidade de universalização dos padrões de produção e consumo praticados nos países que lideraram a revolução industrial. Furtado, o maior expoente do

1 Segundo Celso Furtado (1961), a falta desse esforço teórico teria levado muitos economistas a explicar, por analogia com a experiência das economias desenvolvidas, problemas que só poderiam ser bem equacionados a partir de uma adequada compreensão do fenômeno do subdesenvolvimento. pensamento econômico sobre o tema no Brasil, assinalava então que "o subdesenvolvimento é um processo histórico autônomo, e não uma etapa pela qual tenham, necessariamente, passado as economias que já alcançaram grau superior de desenvolvimento" (Furtado, 1961:180). Portanto, sendo o subdesenvolvimento um fenômeno específico, requereria um esforço de teorização autônomo. ${ }^{1}$

Prebisch, em linhas gerais, argumentava que, até o período da grande depressão dos anos 1930, os países da América Latina tiveram sua dinâmica interna determinada pelo crescimento persistente das exportaçôes, mas que essa alternativa não mais se apresenta- 
va. Isso levaria a concluir que a industrialização seria uma imposição dos fatos e, longe de ser uma escolha, seria a única via de desenvolvimento deixada aos países exportadores de produtos primários. Propunha uma estratégia de crescimento "para dentro", dinamizada por uma "industrialização substitutiva", com forte intervenção do Estado. ${ }^{2}$

Essas idéias passam a influenciar importantes partidos políticos e governos da região, que, sob essas concepções, apresentam propostas de planos nacionais de desenvolvimento econômico e social, com base no avanço do processo de industrialização. No cenário latino-americano, esta é a fase do "planejamento para a mudança”. À medida que o planejamento ganha impulso, os diagnósticos passam a destacar a natureza espacialmente desigual da distribuição de recursos. A proposta centrada na industrialização trazia implícita a contradição entre a aceleração das taxas de crescimento econômico e a equidade interregional. Um crescimento a taxas mais elevadas poderia ser atingido concentrando-se investimentos nas zonas mais desenvolvidas - as de maior produtividade e com um mercado consumidor com grande potencial de ampliação -, embora sob o risco de ampliação das desigualdades regionais. Caberia ao Estado, frente a este risco, compensar as "tendências do mercado", e os quadros técnicos, com freqüência, julgavam ter o poder de atribuir funções e de definir o destino das regiōes. A crença no planejamento é então inconteste, o que leva Mattos a considerá-lo

\begin{abstract}
uma das idéias medulares que marcam as peculiaridades do século XX, na medida em que foi a primeira ocasião ao longo da história da humanidade na qual se generalizou a crença de que o ser humano teria a plena capacidade para empreender e construir um futuro desenhado antecipadamente por ele. (Mattos, 2001:23)
\end{abstract}

No Brasil, a partir da década de 1940, várias foram as tentativas de coordenar, controlar e planejar a economia; mas, até 1956, essas tentativas limitaram-se à formulação de diagnósticos, propostas, medidas setoriais ou de racionalização do processo orçamentário. Até então, o planejamento regional havia se restringido a esforços voltados ao desenvolvimento de bacias hidrográficas e, no plano urbano, a experiências de cidades planejadas segundo princípios do urbanismo funcional-racionalista. É com o Plano de Metas do Governo Juscelino Kubitschek (1956 -1961) que tem início, de modo mais consistente, o planejamento governamental.

A decisão de planejar é essencialmente uma decisão política, pois, segundo Lafer, "é uma tentativa de alocar explicitamente recursos e, implicitamente, valores, através do processo de planejamento e não através dos demais e tradicionais mecanismos do sistema político" (Lafer,1970:30). Na decisão de planejar incide, também, um conjunto de problemas concretos relacionados principalmente à disponibilidade de pessoal técnico qualificado, à existência de informações acessíveis, à capacidade de geração de projetos e programas no setor público e no setor privado e, ainda, à possibilidade de coordenação entre setores e regiōes.

Neste sentido, eram especialmente precárias as condições existentes do Brasil na época. O ingresso no serviço público pelo sistema de mérito (concurso público), embora exigência legal desde a Constituição de 1934, era ainda muito limitado: cerca de 10 a 17\%. Diante dessa situação, foram apresentadas duas alternativas para a preparação do Plano de Metas: prosseguir na tentativa de uma reforma total da administração pública federal ou criar órgãos paralelos à administração normal, os "grupos executivos", que seriam encarregados da implementação do plano, sendo essa a opção adotada. ${ }^{3}$ Além dessas limitações,
2 As idéias básicas de Raul Prebisch foram publicadas em seu artigo "El desarrollo económico de la América Latina y algunos de sus principales problemas". Boletin Económico para América Latina, CEPAL, fevereiro de 1961.

3 É preciso lembrar que em 1958, segundo dados do censo do servidor público federal, havia 229.422 funcionários públicos federais, porém apenas 28.406 eram concursados. Diante desta limitação, foram acionados os órgãos onde predominava o sistema do mérito, como era o caso do BNDE, Banco do Brasil, Superintendência da Moeda e do Crédito-SUMOC, e foram convocadas outras competências disponíveis na administração pública. 
4 Wilson Cano se destaca ao analisar em profundidade as condições da concentração industrial em nosso país. Seu livro Raízes da Concentração Industrial em São Paulo tornou-se um clássico da literatura sobre o tema.

5 Quando se procurou dotar o país de um parque industrial moderno, não se cogitou a imposição de normas quanto à localização, seja em termos regionais ou intra-urbanos. As decisões quanto à localização, ao serem tomadas livremente, pautadas unicamente por critérios de rentabilidade privada, provocam uma elevada concentração territorial, e os diferenciais de renda inter-regionais se ampliam. era restrita a disponibilidade de dados e de informações confiáveis sobre a economia brasileira, o que dificultava o detalhamento e a compatibilização de metas entre setores e entre regióes.

Embora o Plano de Metas seja considerado exitoso, pois a maior parte de seus objetivos teve elevado grau de concretização, as medidas de política econômica adotadas foram baseadas em mecanismos concentradores de renda - não só por estratos sociais como também por regiōes - e tenderam a beneficiar o eixo Rio-São Paulo. ${ }^{4}$ Os desníveis interregionais se ampliaram; mas, estes efeitos da implementação do Plano foram considerados inerentes ao estágio de desenvolvimento do país. Esperava-se que a indústria, no futuro, irradiaria dinamismo aos demais segmentos da economia nacional e conduziria a uma gradual redução das desigualdades inter e intra-regionais.

Entretanto, no decorrer dessa fase da economia brasileira, os desequilíbrios regionais se agravam e as tensóes sociais no Nordeste tornam-se explosivas, passando a ser vistas como uma questão de segurança nacional. É exatamente neste momento que é elaborada a primeira Política de Desenvolvimento Regional sob a condução de Celso Furtado, sendo que a criação da Superintendência de Desenvolvimento do Nordeste (Sudene), em 1959, traduz a tentativa de redefinição das relações entre o centro hegemônico e essa região. ${ }^{5}$

A esmagadora maioria da produção intelectual brasileira sobre a dimensão territorial do desenvolvimento é então voltada para as questôes relativas à concentração industrial e aos chamados "desequilíbrios regionais". O desenvolvimento urbano ainda não é considerado uma questão relevante e não há no Plano de Metas proposições específicas para o seu tratamento. Neste contexto, a construção de Brasília pode ser interpretada muito mais como uma resposta à necessidade de incorporação de novas áreas ao circuito da acumulação capitalista. O próprio Plano de Metas considera Brasília um "ponto de germinação", capaz de constituir-se em uma nova frente de expansão econômica.

À medida que se ampliavam os sistemas de planejamento latino-americanos, considerou-se relevante a formação de especialistas, dado tratar-se de atividade nova, para a qual as diferentes administrações públicas nacionais careciam de pessoal qualificado. A Organização dos Estados Americanos (OEA), a Comissão Econômica para a América Latina (Cepal) e o Instituto Latino-Americano e do Caribe de Planificação Econômica e Social (Ilpes) realizaram os primeiros esforços na formação de recursos humanos para apoiar e guiar os trabalhos de elaboração dos planos econômicos dos países da região. Nesse início, as dimensões regional e urbana foram tratadas de forma marginal, uma vez que o planejamento era dominado por economistas, mais preocupados com a "planificação do desenvolvimento nacional" do que com o impacto social e espacial que poderiam ter os planos que preparavam. (Hardoy, 1990:11).

A acumulação de capital nesta fase - aqui e no mundo - era muito mais localizada em seu circuito de reinversão do que é hoje. As empresas cresciam em cada planta produtiva e esperava-se que a sua inscrição territorial durasse décadas. Assim, os diagnósticos elaborados como primeira etapa do processo de planejamento passam a destacar a importância das desigualdades regionais e a recomendar a incorporação de medidas capazes de enfrentá-las. Os governos dos países latino-americanos procuram então pôr em prática diversas formas de intervenção, com o objetivo de reduzir os chamados desequilíbrios interregionais e aumentar a capacidade de consumo da população de regiōes mais atrasadas. Em quase todos os países da região, são propostas políticas de desconcentração da indústria e de modernização do setor agrícola, de modo a integrar as estratégias de desenvolvimento regional às do planejamento nacional. 
Assim, ao desenvolvimento encontrava-se associada uma metodologia de como planejar, e nos primeiros cursos oferecidos não havia dúvida sobre o que deveria ser ensinado. Os princípios teóricos provinham do pensamento da Cepal e do Ilpes, e os manuais de metodologia para a programação econômica eram as peças-chave da bibliografia básica desses cursos. O pessoal qualificado para atuar nos principais órgãos de planejamento tinha sua formação aprimorada em universidades européias e no Chile, sede da Cepal e do Ilpes.

O longo período de prosperidade do mundo ocidental entre o fim da Segunda Guerra Mundial até meados dos anos 1970, conhecido como os "trinta anos de ouro" do capitalismo, é bruscamente interrompido por uma profunda crise econômica que afeta países como os Estados Unidos, Inglaterra, Alemanha, França. Na América Latina, multiplicam-se os golpes de Estado, gerando um quadro político dominado por regimes altamente repressores dos direitos civis e sociais fundamentais. O Brasil foi "precursor" nesse campo, pois uma década antes da instalação de ditaduras nos outros países latino-americanos, o término do mandato de Juscelino Kubitschek é marcado por grande instabilidade política e econômica, que culmina com o Golpe de Estado de 1964.

\section{O FUTURO DESENHADO AUTORITARIAMENTE}

Ao assumirem a direção do país em março de 1964, os militares adotam um discurso modernizador, comprometido com a retomada do crescimento econômico. Procuram legitimar o exercício do poder argüindo princípios de racionalidade econômica, justificando, assim, a adoção de políticas econômicas concentradoras e excludentes. É no período militar que o planejamento atinge seu auge no país, com a proposição de cinco planos: Plano de Ação Econômica do Governo (PAEG, 1964-67), Plano Estratégico de Desenvolvimento (PED, 1967-69), Primeiro Plano Nacional de Desenvolvimento (I PND, 1969-74), Segundo Plano Nacional de Desenvolvimento (II PND, 1974-79) e Terceiro Plano Nacional de Desenvolvimento (III PND, 1979-84).

O PAEG e o PED geraram poucas mudanças na organização territorial do país. O primeiro era voltado a implementação de políticas de curto prazo que visavam o controle das taxas inflacionárias, a retomada de relações com os organismos internacionais de financiamento e a redução da insatisfação decorrente do déficit habitacional e da precariedade do transporte urbano. Com o PED, o segundo plano do período militar, a recuperação econômica se processa basicamente por meio da utilização da capacidade ociosa da indústria instalada desde o período do Plano de Metas.

É só a partir do I PND que a dimensão espacial do processo de desenvolvimento é vista sob novo formato, diverso dos recortes regionais até então dominantes. A incorporação de novas áreas ao circuito produtivo - tais como o sul do estado do Pará com sua rica reserva mineral de Carajás e as vastas áreas agriculturáveis do Centro-Oeste - impôs um olhar de conjunto mais complexo sobre o território. Desprezando as regiōes tradicionais, a estratégia adotada pelo I PND será baseada nos chamados programas especiais, tais como: Programa Especial do Centro-Oeste; Programa Especial da Região Geoeconômica de Brasília; Programa Especial do Oeste do Paraná; Programa Especial do Grande Dourado; Programa de Desenvolvimento Integrado da Bacia do Araguaia-Tocantins; Programa de Pólos Agropecuários e Agro-minerais da Amazônia; Programa de Áreas Irrigadas do Nordeste; Programa de Desenvolvimento do Cerrado, entre tantos outros. Trata-se de uma 
outra lógica de ocupação territorial, em que o planejamento baseado nas agências regionais de desenvolvimento perde importância.

O II Plano Nacional de Desenvolvimento (II PND) corresponde ao projeto "Brasil: Grande Potência no Final do Século", que é o programa do governo que se inicia em março de 1974. O II PND tem como base um elenco de projetos formulados e implantados diretamente pelo setor público. Se, na etapa anterior, os programas especiais romperam as fronteiras de antigas regiōes e impuseram uma leitura da totalidade do território nacional, no II PND os grandes projetos de desenvolvimento irão definir novas regiōes.

É ainda no âmbito deste plano que a dimensão urbana do desenvolvimento do país adquire maior visibilidade. Ganham vulto as questôes relativas ao "congestionamento" das grandes metrópoles e surgem as primeiras propostas de desconcentração industrial. Para implementar a política de desenvolvimento urbano, foi criada, em 1974, a Comissão Nacional de Regiōes Metropolitanas e Política Urbana (CNPU). O Banco Nacional de Habitação (BNH), que já vinha sendo preparado para assumir encargos relativos ao desenvolvimento urbano, institui programas que abrangem a infra-estrutura (Plano Nacional de Saneamento-Planasa e Projeto Comunidade Urbana para Recuperação Acelerada-Cura), a implantação de novas comunidades urbanas (Projeto de Apoio ao Desenvolvimento dos Pólos Econômicos-Prodepo), o transporte de massa (Programa de Integração de Transportes Urbanos-Piturb) e o planejamento urbano (Programa de Financiamento para o Saneamento-Finansa).

São igualmente ligadas à questão da desconcentração urbana as propostas referentes ao fortalecimento dos centros de porte médio. Estas propostas deram origem ao "Programa de Apoio às Capitais e Cidades de Porte Médio", do Conselho Nacional de Desenvolvimento Urbano (CNDU). As cidades médias teriam - segundo os documentos que embasam esse programa - o papel de propiciar a criação de novos pontos de desenvolvimento no território nacional, de estimular a desconcentração de atividades econômicas e de população, de criar novas oportunidades de emprego e de contribuir para a redução das disparidades interregionais e da concentração da renda. Assim, a preocupação com a intensidade do crescimento demográfico das metrópoles nacionais - que absorviam grande parte do contingente populacional com origem nas zonas rurais das diversas regiōes do país - levou à proposição de uma nova função para as cidades de porte médio: a de "dique" dos fluxos migratórios.

É nesse período que o sistema de planejamento assume um elevado grau de institucionalidade, fazendo com que seja impulsionada a capacitação de pessoal através da criação dos primeiros cursos de pós-graduação no país. Como o projeto dos governos militares era dotar o Brasil de instituiçōes mais fortes no campo da pesquisa tecnológica, foram propostos os primeiros cursos de pós-graduação stricto sensu nas áreas técnicas e em economia. São implantados os programas de mestrado em planejamento urbano e regional na Universidade Federal do Rio Grande do Sul (1970), na Universidade Federal do Rio de Janeiro (1972) e na Universidade Federal de Pernambuco (1975). Em 1967, a Universidade Federal de Minas Gerais já havia criado o Centro de Desenvolvimento e Planejamento Regional-Cedeplar, com a finalidade de abrigar um programa de pesquisa e ensino de pósgraduação na área da Economia Regional. Também em 1967, o Instituto de Pesquisa Econômica Aplicada-Ipea, órgão criado em 1964, realiza diagnósticos inéditos da economia nacional, que propiciaram maior conhecimento da dinâmica de numerosos setores.

A Secretaria de Planejamento da Presidência da República abrigava, além do Ipea, o Instituto de Planejamento (Iplan) e o Centro de Treinamento para o Desenvolvimento 
Econômico (Cendec). Era de tal ordem a importância atribuída à formação de quadros para atuação no sistema de planejamento, que a primeira turma do curso da UFRJ, então sob a responsabilidade da Coordenação dos Programas de Pós-graduação em Engenharia-COPPE, é destinada a técnicos do Banco Nacional de Habitação-BNH, do Serviço Federal de Habitação e Urbanismo-SERFHAU e órgãos do governo federal envolvidos com o planejamento urbano ou regional.

Nesses cursos predominava a formação voltada para as questôes nacionais, uma vez que o projeto dos governos militares era transformar o país em uma grande potência no final do século. Acreditava-se que a senda para o desenvolvimento poderia ser trilhada por meio da elaboração de modelos econométricos e demográficos, baseados na geopolítica e na doutrina da Segurança Nacional. A ênfase nas disciplinas quantitativas - em que a Matriz de Insumo-Produto e os princípios da Programação Linear predominavam - e a crença nos princípios do planejamento racionalista dão o "toque de classe" nos cursos da época. Novas influências se fazem presentes no planejamento territorial, como exemplificam a política francesa de aménagement du territoire e as propostas relativas aos pólos de crescimento. Ambas tiveram ampla aceitação nos meios técnicos e serviram de base a propostas de regionalização do território nacional e a estratégias de desenvolvimento. ${ }^{6}$

Em março de 1979 inicia-se o último governo militar, quando evidenciam-se os sinais da desaceleração do crescimento da economia. No início dos anos 1980, o país enfrenta uma grave recessão: queda nos investimentos e no crescimento do produto interno, aumento das dívidas interna e externa, aceleração do processo inflacionário e renda per capita praticamente estagnada. Nestas circunstâncias, o regime militar se vê deslegitimado, uma vez que a tão propalada "eficiência econômica" não se sustentou na prática. Em 1985, assume o governo um presidente civil, eleito indiretamente pelo Congresso Nacional.

\section{O PLANEJAMENTO dOS NíveIS SUBNACIONAIS}

Novas tendências da dinâmica socioeconômica mundial manifestam-se a partir de meados dos anos 1970, configurando um cenário significativamente diferente daquele do período do segundo pós-guerra, e pondo em cheque o planejamento econômico. Mudanças em curso trazem uma problemática nova quanto ao processo de acumulação de capital: o grande capital passa a ter uma enorme ubiqüidade, podendo localizar-se em qualquer região e produzir em qualquer outra, e esta, por sua vez, não passará de uma opção entre muitas alternativas. Este não é mais um capital enraizado em seu circuito de reinversão. Ao contrário, cada parte desse capital articula-se diretamente com outras em escala global, integrando-se cada vez menos nas estruturas de produção regional ou nacional. Questiona-se, assim, se estariam ocorrendo a "dissolução das regiōes" e a "aniquilação do espaço pelo tempo" (Harvey, 1992), pois, segundo Coraggio, "o capital pode moverse a uma velocidade que guarda pouca relação com os tempos sociais ou os tempos políticos" (Coraggio, 1999:60).

No caso da América Latina, a crise fiscal do Estado e o esgotamento do modelo de crescimento sustentado pela industrialização, fortemente dependente de investimentos do setor público, conduzem à perda de legitimidade, e conseqüente enfraquecimento dos sistemas nacionais de planejamento. Em nosso país, o planejamento passa a ser criticado e rejeitado, posto que identificado com o autoritarismo do período militar, no qual foram
6 A Teoria dos Pólos de Crescimento, desenvolvida por François Perroux e seus colaboradores, surgiu como uma tentativa de resposta aos problemas criados pelos desequilíbrios setoriais e espaciais. Teve larga aceitação nos meios acadêmicos do país, mas sua aplicação encontrou obstáculos por apresentar certa imprecisão em conceitos centrais. 
atualizados conteúdos da dependência econômica, das desigualdades sociais e das disparidades regionais.

Neste cenário, caracterizado por dinâmicas econômicas heterogêneas e distribuição do poder entre diferentes forças sociais, perdem sentido as tentativas de ressuscitar antigas concepções de planejamento. Com a redemocratização do país e as profundas mudanças no capitalismo, a gestão e as políticas públicas tornam-se radicalmente diferentes das que imperavam na época do planejamento centralizado. Por sua vez, surgem novos desafios para os programas de formação de recursos humanos na área do planejamento.

Enquanto na década de 1970 intelectuais de esquerda viam o planejamento como sinônimo de intervenção estatal a serviço dos interesses do capital, nos anos 1980, a rejeição ao planejamento advém dos setores de orientação liberal e se dá por outros motivos: o planejamento estaria servindo mal a esses interesses, uma vez que o Estado deveria apoiar, da forma mais direta possível, a acumulação de capital, eliminando normas, reduzindo exigências legais, oferecendo incentivos fiscais, garantindo segurança aos investimentos e aumentando a fluidez do território.

O discurso de base keynesiana é então substituído por outro, de fundamento neoclássico, segundo o qual é o jogo das forças de mercado que permite assegurar um maior crescimento da economia. A idéia básica que emerge desse corpo teórico é que a política econômica deve ter como função principal contribuir para gerar um ambiente atrativo para o investimento privado, descartando a utilização de políticas que impliquem em intervenção direta do Estado na vida econômica, como defendiam os modelos de desenvolvimento das décadas anteriores.

Como os investidores dirigem-se para as atividades e espaços onde é mais lucrativo investir, resta aos lugares - regióes e cidades - competir entre si por investimentos, o que estimula o discurso que destaca o papel dos governos locais, vistos como agentes capazes de induzir, mobilizar e promover o crescimento econômico. Postula-se que a taxa de crescimento de um determinado país, região ou, até mesmo, de uma cidade é função do capital físico, do capital humano e de conhecimentos detidos pela coletividade. Postula-se, ainda, que caberia aos governos locais assegurar o fornecimento de equipamentos e serviços, baixar custos tributários e conceder subsídios, oferecendo um "ambiente adequado" à conquista da preferência para a localização de empresas. ${ }^{7}$

A nova agenda dos organismos multilaterais - fortemente influenciada pelas idéias regulatório clássico das décadas anteriores não tenha deixado boas lembranças, pois no caso brasileiro é estreitamente relacionado ao autoritarismo do regime militar, a mudança de ênfase para "menos planejamento e mais gestão" encobre uma falácia, uma vez que nenhuma ação (e quanto mais a direção de uma cidade ou país!) prescinde de um mínimo de "planejamento" e também porque o planejamento e a gestão pressupõem ações complementares, não-conflitantes. Essas questões podem ser mais bem entendidas em Carlos Vainer (2002). Marcelo Lopes de Souza (2006) também desenvolve uma longa discussão sobre as mesmas questões.

de desenvolvimento sustentável, competitividade urbana e descentralização administrativa reforça a tendência à valorização do aumento da competitividade das cidades. Desde o início dos anos 1990, estes organismos apóiam projetos e programas nesta direção, quase sempre negociados diretamente com prefeituras, sem interferência do Estado-nação. Abandona-se a perspectiva do desenvolvimento nacional e espera-se que a descentralização da responsabilidade para os governos locais produza o milagre de resolver os problemas de emprego e renda, miséria, questôes ambientais e tantos outros, além de garantir a governabilidade do sistema.

O nacional dá lugar ao local, e a gestão substitui o planejamento. Antes, o debate de concepções e projetos estava centrado em torno de questôes relativas às desigualdades interregionais, às carências de equipamentos urbanos de uso coletivo e à racionalização do uso do solo, e agora a problemática do desenvolvimento remete ao campo da competitividade. Entra em moda o planejamento estratégico - inspirado e baseado no planejamento estratégico empresarial - no qual se advoga que as cidades devem ser administradas como se fossem empresas, competindo entre si para atrair investimentos ou turistas. E a 
expressão empreendedorismo urbano ganha popularidade: o perfil ideal dos novos prefeitos seria o de gestores urbanos, aparentemente mais afeitos aos negócios e ao marketing do que à política. $^{8}$

Assim, com o enfraquecimento do Estado-nação, o planejamento na escala nacional cai em descrédito e os programas de pós-graduação, concebidos para a formação de pessoal na área, são mantidos mas têm seus currículos direcionados para estudos urbanos e regionais, em que o regional perde posição e as questôes intra-urbanas ganham proeminência, inclusive pela relevância dos processos de organização social e política que permitiram o reconhecimento de direitos urbanos na Constituição Federal de 1988. É sintomático da crise do planejamento territorial, porém, que no período de quase 20 anos (entre 1975 e 1993), nenhum novo curso tenha sido implementado na área.

Contudo, evidências empíricas da escala internacional, relacionadas ao desempenho da economia, passaram a indicar que a aceitação incondicional do neoliberalismo não promovia maiores taxas de crescimento e, muito menos, a redução da concentração de renda, seja no plano individual e familiar seja no plano das nações ou regiôes. Ao contrário, esta aceitação provocava o acirramento das desigualdades sociais e espaciais. Com isso, novas vozes aparecem - não apenas aqui como também nos países pioneiros na aplicação dos princípios teóricos e ideológicos do neoliberalismo -, promovendo o debate sobre as políticas de longo prazo. Um debate que, cada vez mais, explicita a centralidade do espaço e, assim, dos conflitos e tensões relacionados à apropriação de recursos estratégicos.

\section{PARA PENSAR O LONGO PRAZO: CONCLUINDO}

O Brasil passou por profundas mudanças em todo o período analisado no presente texto, dando um salto gigantesco em sua base produtiva. Um salto apoiado pela difusão das redes de comunicação e informação, por mudanças institucionais e pelas novas formas de financiamento da economia. A expansão das condições técnicas de produção por todo o território nacional embora alterasse a direção dos fluxos de mercadorias e a natureza dos movimentos migratórios ou, ainda, provocasse a emergência de novas regiōes econômicas, não foi capaz de fazer face à profunda desigualdade dos padrões de vida e às precárias relações de trabalho vigentes no campo e na cidade. Não foi capaz de superar a heterogeneidade estrutural com todas as suas conseqüências sociais.

Desde 2005, o país dá claros sinais de recuperação econômica, e se volta a falar na importância de pensar o longo prazo. Neste contexto, as concepções de desenvolvimento passam a ser mais uma vez tema relevante nos debates sobre os destinos do país. $\mathrm{O}$ enfrentamento teórico e político dessa questão requer avançar nas análises territoriais com pesquisas que busquem identificar a lógica de funcionamento dos vários circuitos de valorização do capital, em seus vínculos com as condições de vida da população. Para que seja reconhecida a dimensão deste desafio, convém destacar que, no país, como afirma Brandão, seguindo as concepções de Tânia Bacelar e Celso Furtado, "nunca as diversidades produtivas, sociais, culturais, espaciais (regionais, urbanas e rurais) foram usadas no sentido positivo. Foram tratadas sempre como desequilíbrios, assimetrias e problemas". (Brandão, 2007: 205) O autor alerta-nos, assim, para a necessidade de que sejam reconhecidas as potencialidades existentes na diversidade, o que implica na articulação entre processos econômicos transescalares e a história, relativamente autônoma, de regióes e lugares.
$8 \mathrm{Na}$ análise de Vainer (op cit), os novos prefeitos teriam a "legitimidade" que os políticos "corrompidos" perderam e poderiam falar em nome de uma vontade úni$c a$, que visaria antes de tudo defender e promover a "cidade" (vista como homogênea), em um processo despolitizador e autoritário, em que desapareceria a cidade do encontro e do confronto entre cidadãos. 
Rosélia Périssé da Silva Piquet é doutora em Economia, professora titular da Universidade Federal do Rio de Janeiro e pesquisadora do CNPq. Coordenadora do Mestrado em Planejamento Regional e Gestão de Cidades, da Universidade Candido Mendes-Campos. E-mail: ropiquet@terra.com.br

Ana Clara Torres Ribeiro é socióloga, doutora pela USP, professora do IPPUR/ UFRJ e pesquisadora do CNPq e da FAPERJ. Coordenadora do Grupo de TrabaIho Desenvolvimento Urbano do CLACSO. E-mail: ana ribeiro@uol.com.br

Artigo recebido em novembro de 2008 e aprovado para publicação em fevereiro de 2009.
Estamos diante, portanto, da necessidade de uma urgente resposta às seguintes perguntas: qual o novo perfil do profissional de nossa área? Quais são os conteúdos disciplinares e técnicos do planejamento socialmente necessário? (Ribeiro, 2002) Podemos reconhecer nossos cursos como ainda voltados à formação de planejadores? Acreditamos ser possível responder afirmativamente a esta última pergunta quando levamos em conta os acúmulos de conhecimento e o fato de o Brasil ser um país continental, periférico e ainda subdesenvolvido, e que requer ser mais bem entendido, sobretudo para propiciar uma apropriação mais justa de seu território. Questionar os interesses constituídos nos mais de cinco mil municípios, distribuídos numa grande variedade de contextos regionais, e estudar o papel exercido pelo capital imobiliário e industrial, pelo agronegócio, pelo capital financeiro, pelas organizaçôes políticas e sociais nas mudanças territoriais são, sem dúvida, tarefas do presente. Além disso, o rescaldo da implantação abrupta e descoordenada das políticas liberais da década de 1990 ainda está por ser feito - uma implantação que trouxe perdas institucionais, destruição de investimentos pretéritos e o agravamento da crise social.

A descentralização administrativa, determinada pela Constituição Federal, traz novas questôes relacionadas à procura de pessoal qualificado. A consolidação deste processo vem exigindo um melhor aparelhamento das administraçóes públicas locais, com o conseqüente aumento da demanda por profissionais para atuar em prefeituras e órgãos públicos em geral. Embora o planejamento, neste âmbito, geralmente se limite a ser um esforço de coordenação administrativa, que não chega ao estágio de produzir efetivas mudanças estruturais, a ampliação de conhecimento de processos econômicos, sócioespaciais e culturais poderá expandir a capacidade de ação do corpo técnico envolvido nas tarefas administrativas.

As mudanças em curso na economia, na administração de recursos e nas formas de organização dos interesses sociais evidenciam a necessidade de que o ensino do planejamento urbano e regional assuma diferentes programas e projetos entre as instituiçôes de ensino, com vistas a atender às demandas regionais e locais de formação profissional (Piquet el al, 2005). O desafio é reconhecer e tratar as diferenças sem gerar perdas teóricas; aderir a modelos desconectados dos contextos investigados; aceitar modismos e cair em casuísmos. Mas, este desafio inclui, também, a superação de generalizações que, por estimularem falsas homogeneidades, pouco avançam no conhecimento da diversidade que caracteriza o país. Sem dúvida, cada vez mais, a sociedade brasileira requer ser mais bem conhecida, o que dependerá da promoção de debates, entre especialistas e atores políticos, centrados na construção de um futuro socialmente mais justo e territorialmente menos desigual.

\section{REFERÊNCIAS BIBLIOGRÁFICAS}

BRANDÃO, C. (2007) Território \& Desenvolvimento - as múltiplas escalas entre o local e o global. Campinas: Editora Unicamp.

CANO, W. (1977) Raizes da concentração industrial em São Paulo. Rio de Janeiro: Difusão Editorial, Coleção Corpo e Alma do Brasil, N. 53.

CORAGGIO, J.L. (1988) Territorios en transición: crítica a la planificación en America Latina. Quito: Ciudad.

FURTADO, C. (1961) Desenvolvimento e subdesenvolvimento. Rio de Janeiro: Fundo de Cultura. 
HARDOY, J. E. (1990) La investigación urbana en América Latina durante las últimas décadas. In: CORAGGIO, J. L. (Org). La investigación urbana en América Latina. Caminos recorridos y por recorrer. Quito: Ciudad.

HARVEY, D. (1992) Condição pós-moderna: uma pesquisa sobre as origens da mudança cultural. São Paulo: Edições Loyola.

INSTITUTO LATINOAMERICANO DE PLANIFICACIÓN ECONOMICA Y SOCIAL (1965) Debates sobre Planejamento. Rio de Janeiro: SEDEGRA.

LAFER, C. (1970) O Planejamento no Brasil: Observaçōes sobre o Plano de Metas (1956-1961). In: LAFER, B.M. (Org). Planejamento no Brasil. São Paulo: Editora Perspectiva.

MATTOS, C. A. (2001) La Gestión Urbano-Regional en un Escenario Globalizado: nuevos retos para su enseñanza. In: Anais do IV Encuentro de Posgrados sobre Desarrollo y Politicas Territoriales y Urbanas de los Paises del Cono Sur. Rio de Janeiro: ANPUR.

PIQUET, R. (2007) Indístria e Território no Brasil Contemporâneo. Rio de Janeiro: Garamond.

PIQUET, R.; LEAL, J. A. A.; TERRA, D. T. (2005) Mestrado Profissional: proposta polêmica no Sistema Brasileiro de Pós-Graduação - o caso do planejamento regional e urbano. Revista Brasileira de Pós-Graduação. Brasília, v. 2, n.4, julho.

PREBISCH, R. (1949). El desarrollo económico de América Latina y algunos de sus principales problemas. ONU.

RIBEIRO, A. C. T. (2002) O ensino do planejamento urbano e regional - propostas à ANPUR. Revista Brasileira de Estudos Urbanos e Regionais, Vol.4, N. 1/2.

SOUZA, M. L. (2006) A Prisão e a Ágora. Reflexões em Torno da Democratização do Planejamento e da Gestão das Cidades. Rio de Janeiro: Bertrand Brasil.

VAINER, C. (2002) Pátria, empresa e mercadoria: notas sobre a estratégia discursiva do Planejamento Estratégico Urbano. In: ARANTES, O.; VAINER, C.; MARICATO, E. (Orgs). A Cidade do Pensamento Único: desmanchando consensos. Petrópolis: Vozes, $3^{\mathrm{a}}$.ed.

A B S T R A C T This article brings, synthetically, the changes observed in the profile of postgraduate courses on Urban and Regional Planning in Brazil in face to the transformations in the economy and in the national planning system. The subject is organized under periods which highlights the master ideas of four phases of the national debate on planning, including its bonds to territorial interpretation: the 50's decade and beginning of the 60's decade (planning to the changing and relevance of the development question); 70's decade and beginning of the 80's decade (technocratic planning and control of the national scale); 80's decade and 90's (predominance of the management and centrality attributed to the forces of the market); current tendencies (return to the development question and growing concern with the long-term planning).

K E Y W O R D S Graduate courses; planning; development; urban system; region. 